DOCTRINA

\title{
Interfase de la reelección de los ayuntamientos y alcaldías en México
}

\author{
Interface reelection of the town halls and city councils in Mexico
}

\section{José René Olivos Campos}

Universidad Autónoma de México

\begin{abstract}
RESUMEN El presente artículo tiene por finalidad exponer el estado legislativo de la elección consecutiva de un periodo de gobierno de los integrantes de los ayuntamientos de 31 estados y de las alcaldías de la Ciudad de México, según las reformas de la Constitución mexicana de 2014, lo cual modifica el modelo democrático de la no reelección de los gobiernos locales que prevaleció en la centuria pasada y con ello introduce retos normativos e institucionales para los procesos políticos electorales democráticos actuales.
\end{abstract}

PALABRAS CLAVE Reelección, ayuntamiento, alcaldías, México.

ABSTRACT The article aims to expose the legislative status of the consecutive election of one more period of the members of the municipalities of thirty-one states and the mayors of Mexico City, according to the reforms of the Mexican Constitution of 2014, which modifies the democratic model of non-reelection of local governments that prevailed in the last century and thus introduces normative and institutional challenges for the current democratic electoral political processes.

KEYWORDS Reelection, town hall, city councils, Mexico.

\section{Introducción}

El presente estudio tiene por objetivo identificar los alcances de los recientes cambios legislativos generados en el ámbito local en materia de la elección consecutiva de los ayuntamientos de 31 estados y de las alcaldías de la Ciudad de México, según lo dispuesto por las reformas a la Constitución Política de los Estados Unidos Mexicanos en materia política y electoral, publicadas en el Diario Oficial de la Federación el 10 de febrero de 2014 . 
Los constituyentes permanentes reestablecieron la elección consecutiva en los gobiernos federales y locales que estuvo vigente en las primeras décadas de la centuria pasada y hoy en día se modifica el paradigma con las reformas constitucionales de 2014, con los cambios a 31 artículos y el régimen transitorio de 21 preceptos, con extensa gama de modalidades para la entrada en vigor de los diversos temas políticos y electorales, en la que incluyó la reelección de los senadores, diputados federales y locales, así como de los gobiernos municipales, con una nueva legislación federal y la armonización que hicieron las entidades federativas en el ámbito de su competencia, de cuya mutación normativa solo se examina lo alcanzado en materia de la reelección en el ámbito de los gobiernos municipales para determinar si ha sido suficiente o no, cuya vigencia permiten determinar sus alcances y apoyar las consideraciones propositivas que estimamos convenientes incluir en una nueva agenda legislativa para el funcionamiento eficaz y oportuno de la reelección en el nuevo orden constitucional democrático.

Desde esta óptica, la hipótesis a demostrar en el presente trabajo es que la legislación de la reelección vigente para el ámbito de cada entidad federativa en México se encuentra inacabada, al no regular debida y cabalmente los procedimientos y las facultades de los órganos estatales competentes para garantizarla y hacerla efectiva.

En este tenor, habremos de dilucidar los atolladeros normativos para la reelección de los gobiernos locales que pueden limitar la consolidación el nuevo patrón de la democracia. Consecuentemente, se tratará de comprender el régimen jurídico para la elección consecutiva de los gobiernos locales de las entidades federativas, con lo que se pretende mejorar la funcionalidad democrática.

\section{Precedentes}

La no reelección en México se estableció a inicios de la centuria pasada, como resultado de la movilización social al no considerar legítimos a los gobernantes que eran impuestos, discrecionales, con opacidad en su actuación, vulneradores de los derechos humanos y represores de cualquier forma de disidencia. En efecto, el Poder Constituyente de 1916-1917 estableció en el artículo 83 de la Constitución la no reelección, promovida por el movimiento que encabezara Francisco I. Madero, lo cual garantizó la no repetición de la etapa reeleccionista de Porfirio Díaz como presidente de México, régimen que se extendió entre 1876 a 1911, con la excepción de cuatro años. Dicho precepto constitucional expresó:

El presidente entrará a ejercer su encargo el 10 de diciembre, durará cuatro años y nunca podrá ser reelecto.

El ciudadano que sustituyere al presidente constitucional en caso de falta absoluta de éste no podrá ser electo presidente para el periodo inmediato. Tampoco podrá ser reelecto presidente para el periodo inmediato el ciudadano que fuere nombrado presidente interino en las faltas temporales del presidente constitucional. 
El precepto original constitucional fue tajante en la prescripción de la reelección presidencial, destacándose el cese de su ejercicio al término del periodo, apegándose al principio de la no reelección. No obstante, la vigencia del referido artículo se reformó el 24 de enero de 1928, en el que se amplió a seis años la duración para ejercer el cargo y a partir de esta modificación los siguientes presidentes electos durarían un solo periodo. Esto permitió la reelección a Álvaro Obregón en 1928, quien había ocupado la presidencia y antes de tomar protesta fue asesinado el 17 de julio de 1928.

La experiencia obregonista derivó en la necesidad de impedir la reelección continua con el objeto de no formar bloques hegemónicos en el sistema presidencial posrevolucionario, con los legisladores del Congreso federal, los gobiernos de los estados y las legislaturas locales.

Después, con la reforma al artículo 83 constitucional publicada el 29 de abril de 1933, se fijó taxativamente la incapacidad del ciudadano que haya desempeñado el cargo de presidente de la República electo popularmente, o con el carácter de interino, provisional o sustituto para que en ningún caso y por ningún motivo volviera a desempeñar el mismo cargo.

Esto se previó también para la reelección continua de los legisladores federales y locales y gobernadores de los estados, que fuera prevista en la Constitución de 1917 hasta el año de 1933, consignadas en los artículos 59 y 116, fracción 2.

En tanto, en el artículo 115, fracción 1, párrafo segundo, constitucional se prohibió que los integrantes de los ayuntamientos electos popularmente fueran reelectos para el periodo inmediato, así como tampoco los electos indirectamente por nombramiento o por designación de alguna autoridad. El texto constitucional expresó:

Los presidentes municipales, regidores y síndicos de los ayuntamientos electos popularmente por elección directa, indirecta, o que por nombramiento o designación de alguna autoridad desempeñen las funciones propias de esos cargos, cualesquiera que sea la denominación que se les dé, podrán ser reelectos una sola vez, para un periodo inmediato.

Los artículos 59, 115 y 116 de la Constitución Federal regularon, entre otros aspectos, durante ocho décadas, 1933 a 2013, que podían ser reelectos los legisladores federales y locales, así como los ayuntamientos después de un periodo de ocupar el cargo. Este paradigma democrático fue modificado con las reformas, adiciones y derogaciones de diversas disposiciones de la Constitución Federal, publicadas en el Diario Oficial de la Federación el 10 de febrero de 2014, como producto de los procesos de la democratización del sistema político desde fines de la centuria pasada, caracterizados por la competitividad y la alternancia en el gobierno dado por los partidos políticos (Lujambio y Vives Segl, 200o); por la ampliación de los derechos políticos; por los pesos y contrapesos dados entre los poderes Ejecutivo y Legislativo federal y locales; así como por las acciones promovidas por intelectuales y diversos actores del sistema político que pugnaron por el establecimiento de referido paradigma. 
Este proceso de rehabilitación jurídica de la elección popular continua de los legisladores federales y locales, así como de los ayuntamientos, se presenta hoy en día como un tema polémico y sensible, en el que se han expresado las ventajas y desventajas por los sectores sociales, organizaciones, fracciones parlamentarias, legisladores y académicos.

\section{Los pros y los contras de la reelección}

Las ventajas de la reelección continua de los legisladores y de los integrantes de los ayuntamientos se centran en torno a la especialización; a la continuidad de los proyectos legislativos y de los programas de gobierno municipal de largo plazo; la mejora de la rendición de cuentas ante el electorado; la mayor autonomía de las legislaturas constituyéndose en un contrapeso efectivo ante el Ejecutivo; y el más estrecho vínculo con el electorado, quienes podrán votar a favor o en contra según el desempeño en el cargo.

Fundamentalmente, éstas fueron las motivaciones en las discusiones de Congreso Constituyente Permanente que diseñaron las reformas a la Constitución en el año 2014, expuestas en los términos siguientes:

- Profesionaliza las carreras políticas: El prospecto de reelegirse y permanecer en el cargo por varios periodos consecutivos motiva a los legisladores y miembros de los ayuntamientos a informarse y aprender sobre diversas materias, a mejorar su técnica legislativa y a trabajar con mayor eficacia y disciplina.

- Genera estabilidad política y legislativa: La presencia de legisladores, presidentes municipales, regidores y síndicos experimentados estabiliza la relación Ejecutivo-Legislativo en el ámbito nacional y en los estados, a pesar de que las cámaras y ayuntamientos estén compuestos por una pluralidad de fuerzas políticas.

- Fortalece el carácter representativo de la democracia: So pena de ser castigados en las urnas, los legisladores, presidentes municipales, regidores y síndicos prestan mayor atención a las preocupaciones de los electores de sus distritos y localidades, para lo cual impulsan propuestas que atienden sus necesidades y defienden sus principales logros.

- Incentiva la elaboración de proyectos de largo plazo: La reelección consecutiva incentiva la elaboración de proyectos que requieren de varios años para gestarse y registrar un impacto, lo que reduce el riesgo de que queden truncos o sean percibidos como ineficaces.

- Propicia una relación armónica entre funcionarios electos y cúpulas partidistas: La estabilidad que implica una relación de largo plazo permite la consolidación armónica de las relaciones de trabajo entre equipos indispensables para las labores legislativas, administrativas y políticas, lo que fortalece la confianza y la familiaridad en el trato. 
- Incrementa la eficacia: El horizonte más largo de los legisladores, alcaldes, regidores y síndicos facilita la discusión y resolución de asuntos políticos de gran trascendencia, cuyas negociaciones requieren de tiempo, conocimientos especializados, profesionalismo y mejor técnica legislativa (Ugalde y Rivera Loret de Mola, 2014).

En contraposición a los argumentos a favor, se encuentran las voces ciudadanas y de académicos que han considerado que con la reelección del legislador y de los integrantes del ayuntamiento, en su último mandato no atenderían las demandas y compromisos con el electorado al no existir temor a que votaran en su contra; la permanencia en su cargo generará incentivos para mantener vínculos con los grupos de intereses particulares, cuyas decisiones de los reelegidos los favorecerían; tendrán ventajas en las contiendas electorales al disponer de medios y recursos, lo que les permitirá un mejor posicionamiento ante el electorado respecto de los ciudadanos postulados para ser electos por primera vez; cuando los integrantes de los ayuntamientos o legisladores se postulen para reelegirse y soliciten licencia al cargo, lo asumirían los suplentes, con lo que tendríamos ayuntamientos y legisladores funcionando integrados por los suplentes por periodos de meses y si esto ocurre en los más de 2.400 municipios y en los congresos, pueden tomar decisiones erróneas y costosas para la sociedad ante la falta de experiencia e impericia para gobernar (Guerra, 2014).

En este contexto, polémico, el hecho es que la reelección consecutiva de los ayuntamientos es inminente al estar prevista en el sistema constitucional mexicano, pero estimamos se requiere de un diseño normativo e institucional de forma integral para que se prevean y se superen muchas de las desventajas anotadas, a fin de que la democratización del régimen político no se desborde en las experiencias pasadas, y en cambio se vincule con la restauración progresiva del Estado constitucional y la protección de los derechos políticos-electorales, así como en los principios y valores de la libertad, igualdad, equidad y justicia, como condiciones necesarias para la gobernación democrática y la acción de los poderes públicos, cuyas dimensiones políticas y normativas asuman nuevos significados y desafíos.

\section{Interfase de la primera generación legislativa de la reelección}

El aseguramiento de la reelección de los legisladores federales y locales, así como de los integrantes de los ayuntamientos, se previó en el texto de la Constitución en los artículos 59; 115, fracción 1, párrafo segundo; y 116, fracción 2, modificados en 2014, así como con las reformas al artículo 122, apartado a), fracción 2, tercer párrafo, publicadas en el Diario Oficial de la Federación el 29 de enero de 2016, las cuales establecen textualmente:

Artículo 59: Los senadores podrán ser electos hasta por dos periodos consecutivos y los diputados al Congreso de la Unión hasta por cuatro periodos consecutivos. La postulación solo podrá ser realizada por el mismo partido o por cualquiera de los partidos 
integrantes de la coalición que los hubieren postulado, salvo que hayan renunciado o perdido su militancia antes de la mitad de su mandato.

Artículo 115: Los estados adoptarán, para su régimen interior, la forma de gobierno republicano, representativo, democrático, laico y popular, teniendo como base de su división territorial y de su organización política y administrativa, el municipio libre, conforme a las bases siguientes:

1) Cada municipio será gobernado por un ayuntamiento de elección popular directa, integrado por un presidente municipal y el número de regidores y síndicos que la ley determine. La competencia que esta Constitución otorga al gobierno municipal se ejercerá por el ayuntamiento de manera exclusiva y no habrá autoridad intermedia alguna entre éste y el gobierno del Estado.

Las constituciones de los estados deberán establecer la elección consecutiva para el mismo cargo de presidentes municipales, regidores y síndicos, por un periodo adicional, siempre y cuando el periodo del mandato de los ayuntamientos no sea superior a tres años. La postulación solo podrá ser realizada por el mismo partido o por cualquiera de los partidos integrantes de la coalición que lo hubieren postulado, salvo que hayan renunciado o perdido su militancia antes de la mitad de su mandato.

Artículo 116: [...] 2) Las constituciones estatales deberán establecer la elección consecutiva de los diputados a las legislaturas de los estados, hasta por cuatro periodos consecutivos. La postulación solo podrá ser realizada por el mismo partido o por cualquiera de los partidos integrantes de la coalición que los hubieren postulado, salvo que hayan renunciado o perdido su militancia antes de la mitad de su mandato.

Artículo 122: a) [... 2) En la Constitución Política de la Ciudad de México se establecerá que los diputados a la Legislatura podrán ser electos hasta por cuatro periodos consecutivos. La postulación deberá ser realizada por el mismo partido o por cualquiera de los partidos integrantes de la coalición que los hubieren postulado, salvo que hayan renunciado o perdido su militancia antes de la mitad de su mandato. [...]

4) El gobierno de las demarcaciones territoriales de la Ciudad de México estará a cargo de las alcaldías [...] La integración, organización administrativa y facultades de las alcaldías se establecerán en la Constitución Política y leyes locales, las que se sujetarán a los principios siguientes:

a) Las alcaldías son órganos político-administrativos que se integran por un alcalde y por un Concejo electos por votación universal, libre, secreta y directa, para un periodo de tres años. [...]

b) La Constitución Política de la Ciudad de México deberá establecer la elección consecutiva para el mismo cargo de alcalde y concejales por un periodo adicional.

En dichos preceptos constitucionales se estableció que los senadores podrán ser electos hasta por dos periodos y los diputados hasta por cuatro periodos consecutivos. Por su parte, los estados deberán prever en sus constituciones locales las legislaturas hasta por cuatro periodos consecutivos y los ayuntamientos por un periodo más elección consecutiva siempre que dicho periodo no sea superior a tres años, mientras que en la Ciudad de México se prevé para las alcaldías un periodo adicional. Esto ha venido tomando forma con la primera generación legislativa expedida por los estados. 
Podemos caracterizar esta etapa como una interfase normativa entre el viejo orden legislativo, en el que estuvo vigente la no reelección que no acaba por concluir, y el nuevo orden de la elección consecutiva que no termina por nacer con toda la ingeniería constitucional y legal democrática.

Esto se puede advertir con la heterogeneidad constitucional y legal que existen en la materia de la reelección de ayuntamientos y alcaldías. Mientras algunos estados no la han regulado, otros sí lo han hecho, y en estos últimos casos sus leyes secundarias resultan insuficientes al no establecer requisitos, condiciones y términos que garanticen los principios, normas y valores constitucionales democráticos, como la equidad e igualdad que debe regir en los procesos electorales.

En las constituciones y leyes secundarias locales se observa la heterogeneidad que prevalece en la elección consecutiva de los integrantes de los ayuntamientos de 31 estados y las alcaldías del estado de la Ciudad de México. En 26 estados se regula respectivamente en las constituciones locales la elección de los integrantes de los ayuntamiento para un periodo adicional consecutivo para presidentes municipales, síndicos y regidores, como son las entidades federativas de Aguascalientes (Constitución Política del Estado de Aguascalientes, artículo 72) Baja California (Constitución Política del Estado Libre y Soberano de Baja California, artículo 78), Baja California Sur (Constitución Política del Estado de Baja California Sur, artículo 141), Campeche (Constitución Política del Estado de Campeche, artículo 102), Chiapas (Constitución Política del Estado de Chiapas, artículo 69), Chihuahua (Constitución Política del Estado Libre y Soberano de Chihuahua, artículo 126), Coahuila (Constitución Política del Estado de Coahuila de Zaragoza, artículo 30), Colima (Constitución Política del Estado Libre y Soberano de Colima, artículo 87), Durango (Constitución Política del Estado de Durango, artículo 149), Guanajuato (Constitución Política para el Estado de Guanajuato, artículo 113), Guerrero (Constitución Política del Estado Libre y Soberano de Guerrero, artículo 176), Jalisco (Constitución Política del Estado de Jalisco, artículo 73), México (Constitución Política del Estado Libre y Soberano del Estado de México, artículo 116), Michoacán (Constitución Política del Estado Libre y Soberano de Michoacán, artículo 116), Morelos (Constitución Política del Estado Libre y Soberano del Estado de Morelos, artículo 112), Nuevo León (Constitución Política del Estado Libre y Soberano del Estado de Nuevo León, artículo 124), Oaxaca (Constitución Política del Estado Libre y Soberano de Oaxaca, artículo 29), Querétaro (Constitución Política del Estado de Querétaro, artículo 35), San Luis Potosí (Constitución Política del Estado de San Luis Potosí, artículo 114), Sinaloa (Constitución Política del Estado de Sinaloa, artículo 117), Sonora (Constitución Política del Estado de Sonora, artículo 131), Tabasco (Constitución Política del Estado Libre y Soberano de Tabasco, artículo 64), Tlaxcala (Constitución Política del Estado Libre y Soberano de Tlaxcala, artículo 90), Tamaulipas (Constitución Política del Estado de Tamaulipas, artículo 130), Yucatán (Constitución Política del Estado de Yucatán, artículo 77) y Zacatecas (Constitución Política del Estado Libre y Soberano de Zacatecas, artículo 118). 
La Constitución Política de la Ciudad de México publicada en la Gaceta Oficial el 5 de febrero de 2017, en su artículo 53, apartado a), numeral 6, prevé que los alcaldes y concejales que integrarán las alcaldías podrán ser electos consecutivamente por un periodo adicional.

En los estados de Hidalgo, Nayarit, Puebla, Quintana Roo y Veracruz no han reformado sus respectivas constituciones locales para la elección consecutiva de dos periodos para los integrantes de los ayuntamientos, lo que representa un rezago normativo para regular dicha materia y constituye un déficit para la gobernación democrática.

En diecinueve estados se han expedido las leyes reglamentarias de las respectivas constituciones locales para regular las elecciones hasta dos periodos de los integrantes de los ayuntamientos, de las entidades federativas de Aguascalientes (Código Electoral del Estado de Aguascalientes, artículos 143, 147 y 378), Baja California (Ley Electoral del Estado de Baja California, artículos 30 y 145), Baja California Sur (Ley Electoral del Estado de Baja California Sur, artículos 53, 105 y 106), Campeche (Ley de Instituciones y Procedimientos Electorales de Campeche, artículo 18), Chiapas (Código de Elecciones y Participación Ciudadana de Chiapas, artículo 26), Chihuahua (Código de Elecciones y Participación Ciudadana de Chihuahua, artículo 26), Colima (Código Electoral del Estado de Colima, artículo 24), Durango (Ley de Instituciones y Procedimientos Electorales del Estado de Durango, artículo 187), Guerrero (Ley de Procedimientos Electorales del Estado de Guerrero, artículos 14 y 273), Jalisco (Código Electoral y de Participación Ciudadana del Estado de Jalisco, artículos 12 y 241), México (Código Electoral del Estado de México, artículos 18 y 252), Nuevo León (Ley Electoral del Estado de Nuevo León, artículo 144), Oaxaca (Ley de Instituciones y Procedimientos Electorales de Oaxaca, artículo 20), Puebla (Código de Instituciones y Procedimientos Electorales del Estado de Puebla, artículo 18), Querétaro (Ley Electoral del Estado de Querétaro, artículos 15 y 198), San Luis Potosí (Ley Electoral del Estado de San Luis Potosí, artículo 28), Sinaloa (Ley de Instituciones y Procedimientos Electorales del Estado de Sinaloa, artículo 14), Tamaulipas (Ley Electoral del Estado de Tamaulipas, artículo 194) y Zacatecas (Ley Electoral del Estado de Zacatecas, artículo 22).

La Ciudad de México habrá de reglamentar la Constitución local cuando ésta se expida por el Poder Constituyente, que deberá regular sobre la reelección de alcaldes y concejales.

En doce entidades federativas no se ha establecido las leyes que regulen las disposiciones constitucionales respectivas para la reelección de presidentes, síndicos y regidores integrantes de los ayuntamientos, como son los estados de Coahuila, Guanajuato, Hidalgo, Michoacán, Morelos, Nayarit, Quintana Roo, Sonora, Tabasco, Tlaxcala, Veracruz y Yucatán, así como tampoco en la Ciudad de México para reelegir alcaldes y concejales. Asimismo, en ciertos estados existe la necesidad de que se legisle en dicha materia con oportunidad, apego a los principios, normas y valores constitucionales democráticos.

También se advierten algunas omisiones de lo prescrito por la Constitución Federal en lo ya vigente en las normativas locales. Por ejemplo, en el estado de Michoacán exis- 
te la omisión en la constitución local, al no considerar de forma completa lo previsto en los artículos 115, fracción 1, párrafo segundo, y 116, fracción 2, párrafo segundo de la Constitución Federal en materia de reelección. La Constitución Política del Estado Libre y Soberano de Michoacán de Ocampo no fija en sus artículos 20, 116 o 117 el mandato de la Constitución Federal que establece que para las diputaciones y los ayuntamientos la postulación solo podrá ser efectuada por el mismo partido o por cualquiera de los partidos integrantes de la coalición que lo hubieren postulado, salvo que hayan renunciado o perdido su militancia antes de la mitad de su mandato.

Esta omisión bien podría subsanarse con las reformas y adiciones a la propia constitución local o en su legislación electoral, a fin de cumplir con el mandato de la Constitución Federal.

\section{Consideraciones}

En la interfase normativa de la reelección de los integrantes de los ayuntamientos y alcaldías de las entidades federativas en México, resulta crucial que se lleven a cabo las reformas legislativas necesarias para que la implementación de la reelección se ejecute con la seguridad jurídica que se requiere en el sistema democrático.

Estimamos que la implementación de la reelección debería entenderse vinculada al reconocimiento y garantía de otros derechos humanos en la Constitución y de los tratados internacionales que el Estado mexicano es parte, que sirvan para controlar las acciones de los gobernantes reelectos, para promover el debate, el disenso, la opinión pública que condicione la formación de sus decisiones y acciones, así como para el logro de la cooperación en la formulación, aprobación y aplicación de las políticas.

Los cambios deben arribarse desde el enfoque integral, cuyas vertientes, entre otras, serían la instauración y vigencia de los mecanismos de la democracia participativa, la rendición de cuentas y la derogación del fuero constitucional de los servidores públicos.

En la vertiente de la democracia participativa, debería impulsarse la revocación del mandato de forma simultánea con las reformas y adiciones legislativas de la reelección, para que la desposesión del mandato sea un mecanismo de control ciudadano ante el ejercicio de poder de los gobernantes que ante su último periodo no atienda las demandas y compromisos con el electorado al no existir temor a que votaran en su contra, o se advierta que con sus decisiones pueda favorecer a los grupos de intereses particulares o fáctico, o bien ante la impericia o negligencia para gobernar con decisiones erróneas y costosas para la sociedad, conduzca a la quiebra de las finanzas públicas con altos deterioros para la colectividad.

Aun cuando no deja de advertirse la gran resistencia para el reconocimiento de un derecho político a la revocación del mandato por parte del Constituyente Permanente, representada por más de cuarenta iniciativas impulsadas por los propios legisladores federales sin que hayan prosperado, o las declaraciones de su inaplicación en aquellos estados en que se encuentra prevista en las constituciones locales, como sucede en las constituciones de los estados de Chihuahua (sentencia de la Suprema Corte de Justi- 
cia de la Nación, acción de inconstitucionalidad 63/2009 y sus acumuladas 64/2009 y 65/2009) y Yucatán (sentencia de la Suprema Corte de Justicia de la Nación, acción de inconstitucionalidad 8/2010) por parte de la Suprema Corte de Justicia de la Nación, según las acciones de inconstitucionalidad que fueron promovidas, en cuya resolución se ha establecido que en la Constitución Federal no se prevé tal figura para sancionar a los funcionarios electos y solo procede contra ellos responsabilidades de naturaleza penal, administrativa o civil.

También otras entidades federativas expresamente han reconocido la revocación del mandato, como los estados de Aguascalientes, Guerrero, Morelos y de la Ciudad de México, con lo que se ha instaurado de manera gradual y azarosa en el presente siglo, en el constitucionalismo y leyes secundarias locales, adelantándose los estados en esta materia a la Constitución Federal.

Éstos nos parecen avances importantes pese a los obstáculos señalados, que resulta relevante para el ejercicio del gobierno democrático y para dar estabilidad al sistema político, que debiera complementar a la democracia representativa en su vertiente de reelección, con lo que se reivindicaría el principio de que el poder dimana del pueblo.

También habría que impulsar otros mecanismos de participación ciudadana, como el establecimiento de un observatorio ciudadano, el cual debiera constituirse en una figura que permita el escrutinio de los gobernantes y publicite el desempeño de su gestión, como parte de los componentes de la rendición de cuentas a la ciudadanía, por la confianza que ésta ha depositado en los gobernantes.

Una segunda vertiente comprendería la rendición de cuentas, la cual constituye contenidos públicos que resultan ineludibles para la forma de obrar de los gobiernos para gobernar democráticamente ante los atropellos de derechos, arbitrariedades y corrupción que hacen los servidores públicos, la instauración de la cleptocracia, la impunidad y los privilegios, que han causado crisis fiscales, colapsos de la economía nacional, lo que ha tenido por sustento el secreto (Weber, 1977: 92; 1990: 745) y la opacidad ${ }^{1}$ de los asuntos públicos como formas de dominación en el ejercicio del poder político.

No es casual que en el Índice de Percepción de la Corrupción, elaborado anualmente por la organización denominada Transparencia Internacional, México se ubicó en la posición 95 de 183 países en el año 2015 - lugar en promedio ha mantenido durante una década desde el año 2005-, con una calificación de 35, en una escala en que cero corresponde al país más corrupto y cien significa que no tiene corrupción.

Esto también se corrobora con el Barómetro Global de la Corrupción, que se calcula a partir de una encuesta, y según la cual el 71\% de los mexicanos afirma que la corrupción en el país ha aumentado en los últimos dos años. Por su parte, el $52 \%$ de los mexicanos consideró que la lucha del gobierno contra la corrupción era ineficaz,

1. Por opacidad se comprende el no dar a conocer al público los actos o el desempeño en el ejercicio de los recursos, la gestión y funciones públicas de los agentes del gobierno y de la administración pública, o cuando se da a conocer datos que no resultan fidedignos de su actuación, decisiones o resultado. 
y el $55 \%$ pensaba que era indispensable reducir la corrupción para que la democracia funcionará mejor. ${ }^{2}$

Ante tales situaciones descritas, la rendición de cuentas apunta a generar una perspectiva para lograr responsabilidades de los sujetos obligados, con el fin de combatir la corrupción y fortalecer la vida institucional democrática.

Entendemos por «rendición de cuentas» aquella actividad en que los servidores públicos deben informar, reportar, explicar, justificar, fundar, motivar y responsabilizarse de sus acciones y actos ante otro agente del gobierno o de la administración pública, en todos sus aspectos, en el régimen jurídico que prescribe las obligaciones y que deben cumplir los servidores públicos en su desempeño gubernamental o administrativo.

En tanto, comprendemos «transparencia» como todo sujeto obligado al escrutinio público que prevén los ordenamientos jurídicos, y que debe proporcionar, suministrar $\mathrm{y}$ dar visibilidad a la información que posea de forma fidedigna, veraz y oportuna a toda persona, lo cual debe ser garantizado por el Estado y con responsabilidades definidas ante el incumplimiento.

Los procesos, procedimientos y mecanismos para la rendición de cuentas y la transparencia se han estructurado con normas jurídicas, órganos de gobierno e instancias administrativas de control, fiscalización, vigilancia, revisión y sanción, componentes cruciales para el comportamiento legal y responsable de los servidores públicos en el desempeño de sus funciones, así como para el enlace y la comunicación que favorece a los ciudadanos a acceder al conocimiento del cometido de la función pública abierta y sometida al escrutinio público, con lo que la gestión de los asuntos comunes sea asegurada según los mandatos constitucionales y legales.

Hoy en día, se emprenden acciones complementadas con las leyes del sistema nacional anticorrupción, como la Ley General del Sistema Nacional Anticorrupción, la Ley de Responsabilidades Administrativas, la Ley del Tribunal de Justicia Administrativa y las normas que habrán de modificarse, como la Ley de Fiscalización y Rendición de Cuentas de la Federación, y la Ley Orgánica de la Administración Pública Federal, con las que deberán armonizarse las leyes locales en estas materias a fin de hacer efectivo un sistema nacional anticorrupción.

Esto contribuiría a evitar el efecto corruptor que se actualiza cuando los gobernantes municipales reelegidos tengan conductas fuera de todo cauce constitucional y legal, ex ante, durante y expost, con lo que se invalidaría la confianza depositada de electores.

Dentro de las medidas que se pueden considerar para el control y confianza de quien se postule como candidato a ocupar un cargo consecutivo en los ayuntamientos o alcaldías está el contar con evaluaciones de salud, examen toxicológico y antecedentes de probidad validados por el Centro de Investigación y Seguridad Nacional, a fin de acreditar la solvencia física, moral y proba.

Una tercera vertiente que resulta relevante es la derogación del fuero constitucional

2. «Conoce los resultados del Barómetro Global de la Corrupción 2013», Transparencia Mexicana, 9 de agosto de 2013, disponible en http://bit.ly/2CP6ixe. 
actualmente previsto en los artículos 74, 110 y 111 y en la Ley Federal sobre Responsabilidades de Servidores Públicos reglamentaria — tratándose de acusaciones sobre delitos federales-, y en los estados las constituciones locales respectivas y leyes de responsabilidad de los servidores públicos.

En esta nueva etapa de reelección, resulta incongruente con los derechos de igualdad que prescribe la propia Constitución Federal y los tratados internacionales que aún se siga con privilegios otorgados a los servidores públicos, lo que ha implicado inmunidad al protegerlos contra acusaciones, y que se les conceda privilegios procesales frente al resto de la población, lo que resulta en estos tiempos un contrasentido sustancial de la igualdad de los derechos humanos. Así, se han presentado casos frecuentes de ciertos servidores públicos que gozan del fuero constitucional y han transgredido de manera impune las leyes, disposiciones que deben ser acatadas por los funcionarios.

Sobre la base de los principios, normas y valores que rigen los derechos humanos de igualdad ante la ley vinculados a la imparcialidad y acceso a la justicia, no debería existir la institución del fuero constitucional de los servidores públicos que tendrán por base la reelección. Algunos estados ya han derogado la figura del fuero constitucional, como es el caso de Jalisco, Veracruz y Campeche; con ello se adelantan a lo que debiera establecerse en la Constitución Federal.

Otro obstáculo que habría que solventar para el fortalecimiento de la vida democrática en la instauración de la reelección es reducir los índices de desigualdad e inseguridad que persisten y que pueden vulnerar la voluntad de los electores por los grupos de interés.

\section{A modo de conclusión}

En la propuesta normativa, para estar acordes con los principios y normas constitucionales de equidad, igualdad y legalidad, estimamos los temas enunciativos que debieran considerarse en la reforma electoral estatal.

En la solicitud de registro de los ciudadanos postulados a la reelección, apreciamos que deberá satisfacer los requisitos de elegibilidad constitucionales y legales previstos para acreditar que los cumple en tiempo y forma. Además, debe manifestar por escrito bajo protesta de decir verdad donde se fijen los periodos para los que ha sido electo en ese cargo y la manifestación de estar cumpliendo los límites constitucionales de reelección, para dar certeza a la hipótesis reeleccionista.

Consideramos que hay que establecer que el tiempo de separación del cargo para quienes pretendan reelegirse debe ser de noventa días antes de la elección, con el propósito de garantizar el principio de equidad, a partir del periodo que se fija por la propia Constitución para los funcionarios que pretendan postularse a algún cargo de elección popular.

Creemos que es necesario consignar en la normativa electoral de los estados que la postulación de reelección para diputados e integrantes de los ayuntamientos y alcaldías solo podrá ser efectuada por el mismo partido o por cualquiera de los partidos 
integrantes de la coalición o de las candidaturas comunes que los hubieren postulado, salvo que hayan renunciado o perdido su militancia antes de la mitad de su mandato, lo que permitiría la armonización con los artículos 115, fracción 1, párrafo segundo, y 122, fracción 2, párrafo segundo de la Constitución Federal.

En el caso de munícipes electos como candidatos independientes, solo podrán postularse para la reelección con la misma calidad de candidato independiente, o bien cuando éste pretenda postularse por un partido político, deberá acreditar su afiliación o militancia en el partido político antes de la mitad de su mandato del periodo en el ejercicio del cargo, caso en el que sí podrá postularse para reelección por dicho partido. Esta exigencia se comprende por analogía cuando se concede la misma prerrogativa a los candidatos postulados por los partidos políticos y coaliciones.

Estimo que la solicitud de registro de las listas de representación proporcional debiera regularse en términos de que manifiesten, en el caso de los integrantes de cada lista propuesta por los partidos políticos cuando están optando por reelegirse en sus cargos bajo este principio, el número de veces que han ocupado la misma posición de manera consecutiva.

La renovación de la reelección implica adoptar medidas normativas e institucionales que conduzcan a la mejora de la integridad democrática y no corruptores, con las acciones responsables de los actores políticos, de nuestros legisladores democráticos, con la participación ciudadana y la utilización de recursos y medios para potenciar la equidad, la legalidad y la igualdad en la contienda electoral, en que deben prevalecer los elementos jurídicos y políticos, constitutivos del ciudadano, de modo que la democracia sea entendida y hecha realidad en el sentido extenso, como lo estableció Daniel Webster, en 1830: «Un gobierno del pueblo, hecho para el pueblo, por el pueblo y responsable ante el» (Lijphart, 2000: 13).

\section{Referencias}

Guerra, Yomara (2014). «La reelección inmediata de los legisladores en México». En Adrián Gallardo y Jesús Silva (coordinadores), Reforma electoral y cambio de régimen político y de gobierno. Ciudad de México: Fundación Colosio y MA Porrua.

Lijphart, Arend (2000). Modelos de la democracia: Formas de gobierno y resultados de treinta y seis países. Barcelona: Ariel.

Lujambio, Alfonso y Horacio Vives Segl (200o). El poder compartido: Un ensayo sobre la democratización mexicana. Ciudad de México: Océano.

UGaLde, Luis Carlos y Gustavo Rivera Loret de Mola (2014). «La reelección en México: Antecedentes y retos de la reforma electoral 2013». Revista Mexicana de Derecho Electoral, 6: 189-210. Disponible en http://bit.ly/2VxSIpp.

Weber, Max (1977). ¿Qué es la burocracia?. Buenos Aires: La Pléyade.

-. (1990). Economía y sociedad. Ciudad de México: Fondo de Cultura Económica. 


\section{Sobre el autor}

José René Olivos Campos es doctor en Derecho con mención honorífica por la Universidad Autónoma de México. Investigador nacional nivel 2 del Sistema Nacional de Investigadores. Su correo electrónico es jrolivos@yahoo.com. 